\title{
Which Ministry Takes Obesity Seriously?
}

\author{
Stephan Rössner \\ Obesity Unit M 73, Karolinska University Hospital Huddinge, Stockholm, Sweden
}

A common remark by referees when scrutinising submitted manuscripts to various journals in the field of obesity research is the statement that the introduction is generally redundant. By now there is no need to inform the readership about the obesity epidemic and its consequences on a global scale. Generally it is preaching to the converted to state that we are facing an enormous challenge in a century when more people will die of over-nutrition than under-nutrition and starvation. IASO [1] provides continuous update on the global situation, and an extensive global assessment was recently published in Lancet [2].

At the same time obesiologists are frustrated by the fact that so little seems to happen as regards the political action to combat the obesity epidemic. Ministers of health have convened and signed declarations, and at a top level there is generally a sense that actions need to be taken but uncertainty as what should be done and what is worthwhile, since it has not been possible to demonstrate any real long-lasting effective tools for prevention and intervention [3].

In a recent meeting a minister of health from the southern hemisphere summarised his personal frustration: 'Every time I sign a document setting resources aside for actions towards obesity I never know if that money has been wisely spent'. This is an anonymous statement indeed reflecting the complexity of the problem.

Obviously at the national level the ministers of health should be responsible for the coherent strategic approach to combat obesity, but there is general awareness that such a concerted action needs the involvement of many more official bodies. The Netherlands are an example of a society where an integrated approach has been developed [4].

OECD has summarised the situation as follows [5]:

- Obesity is indeed dangerous; an individual with a BMI value around $40 \mathrm{~kg} / \mathrm{m}^{2}$ (grade III obesity) runs the same risk of premature death as a smoker.
- Obese people are costly to society.

- Prevention is the obvious first line of strategy, but effects are difficult to measure on the individual level.

- Social aspects: Women are more stigmatized than men, obesity remains a problem of lower socio-economic classes, children are becoming more vulnerable, and obesity is an obstacle for access to the labour market.

It is therefore interesting that a report, showing considerable insight in the problem in Sweden, was published not by the Swedish ministry of health but by the ministry of finance [5]. This ministry has set down a task force with an expert group for studies in public economy, which has in detail analysed the financial implications of the obesity epidemic.

The basic facts, reported in the study, are trivial for anyone involved in obesity-related projects and gives a background, which is all too familiar. But then the expert group continues to calculate the costs at the individual and to societal levels. With a conservative approach that an obese individual may lose 3 years of life, this can be estimated to SEK 2.1 million (EUR 220,000.-). This would mean that the total individual cost in Sweden (population size $\approx 9.3$ million) will be around SEK 35 million (EUR 3.6 million) per year. This does not include data on those who are only pre-obese $\left(25 \mathrm{~kg} / \mathrm{m}^{2}\right.$ $\left.\leq \mathrm{BMI}<30 \mathrm{~kg} / \mathrm{m}^{2}\right)$. Calculations based on the situation in the year 2003 suggested a loss of production due to sickness absence and health care costs related to both overweight and obesity amounting to SEK 15 billion (EUR 1.6 billion). By the year 2020 these costs have been calculated to rise by between $40 \%$ and even up to $80 \%$.

Of course the age of the individual will affect how great the impact is on public expenditure, and the ages of the obese individuals in these analyses are not known. This means that, in spite of serious attempts to calculate the effects, the economical impact of overweight and obesity cannot be fully determined. With an autonomous pension system loss of pro-

\section{KARGER \\ Fax +497614520714 \\ Information@Karger.de}

www.karger.com (c) 2011 S. Karger GmbH, Freiburg

$1662-4025 / 11 / 0045-0339 \$ 38.00 / 0$

Accessible online at:

www.karger.com/ofa
Prof. Dr. Stephan Rössner

Obesity Unit M 73, Karolinska University Hospital Huddinge

14186 Stockholm, Sweden

Tel. +4685858 2483

Stephan@Rossner.se 
duction due to premature death leads to lower pensions for other pensioners, if loss of production would result in reduced growth. However, at the same time premature death means that pension rights are not used, which creates survival bonuses for the other pensioners.

The Swedish expert group (ESO) discusses how much a state should care about the production and consumption of calories of its citizens and to what extent it is reasonable to influence their lifestyle. The arguments for state intervention are summarised by ESO in four points.

i) Overweight and obesity cause classic externalities in the form of costs that are not borne by those who cause them, but by others or by society at large. The public sector cost for health care and social insurance as a result of overweight and obesity alone has been estimated at $0.6 \%$ of the Swedish gross domestic product (GDP) in the year of 2003, probably a severe underestimation.

ii) There is a peer group effect. Norms which are created within social groups, such as sex, class, ethnic groups or family values, have positive or negative external effects on the health of others. Influencing the diet and lifestyle activity of individuals will have an effect on those around them such as children and relatives. The individual's decision making concerning caloric consumption will partly be based on the observation of peers. It has been demonstrated that weight tracks within social clusters [6].

iii) State intervention may be motivated by paternalistic altruism. People may be willing to pay to help individuals who harm themselves, but such willingness is more likely to exist if those who pay know how these resources are utilised. This problem will become particularly relevant in situations where the donors may suspect that the recipients lack self-control and do not use the resources given as intended. The public sector is a greater opportunity than others to use paternalistic measures, and the presence of paternalistic altruism thus becomes a reason for public intervention.

iv) Is society concerned that producers use the information to their advantage to increase the food consumption of products which are cheap to produce but less healthy?
The committee concludes that there are several reasons why a state should do something about the weight trap. Several approaches are discussed including measures directed at school children, targeted or universal taxes and improved transportation opportunities such as bicycle lanes - in summary suggestions which have indeed been discussed over the years and do not add anything new but re-iterates the need for a structured concerted activity.

In discussing the possibility of 'sin taxes' the Swedish experts are surprisingly vague. After all, they argue that the literature is not that consistently convincing, and in some cases tax effects, whether using the carrot or the stick principle, will affect those already prepared to make changes for the better. The Swedish experts are also concerned about the practical implications of tax interference, although there is awareness about the success in prevention when reducing the percentage of e.g. smokers.

Sweden is a homogenous country in spite of the immigration over the last decades. Its population is relatively healthy, survived the recent financial crisis better than many other countries and has a well organised administrative structure, which makes it a haven for epidemiological research. Data on numerous aspects of the individual's life can be tracked in databases, which are openly available to scientists. Studies such as the Västerbotten monitoring of health in a selected target population have shown that general public health examinations can be effective [7]. But since overweight and obesity problems affect such a large proportion of the population, it is not enough to approach only high-risk individuals. Although the incidence of complications to obesity percentagewise will be much lower in the pre-obese population, this segment is so numerous that the overall number of cases in this group will be larger.

Will the Swedish ministry of health pick up the report from the ministry of finance with its 222 references and apply it? Nobody is certain that this will happen. For a clinician and researcher who has spent about 35 years in the obesity field depressingly little governmental action has been seen. Some countries show exceptions, such as the Dutch approach [4]. Furthermore, the recent massive Lancet summary should act as an important and timely whistle blower [2].

\section{References}

1 www.iaso.org.

2 Finucane MM, Stevens GA, Cowan MJ, Danaei G, Paciorek CJ Singh GM, et al: National, regional and global trends in body-mass index since 1980: systematic analysis of health examination surveys and epidemiological studies with 960 country-years and 9.1 million participants. Lancet 2011;377: 557-567.

3 www.euro.who.int/obesity/conference2006.
4. Renders CM, Halberstadt J, Frenkel CS, Rosenmöller P, Seidell JC, Hirasing RA: Tackling the problem of overweight and obesity: the Dutch approach. Obes Facts 2010;3:267-272.

5 Sassi F: Obesity and the Economics of Prevention. Fit Not Fat.. Paris, OECD Publishing, 2010.

6 Christakis NA, Fowler JH: The spread of obesity in large social network over 32 years. N Engl J Med 2007:357:370-379.
8. Weinehall L, Hellsten G, Boman K, Hallmans G, Asplund K, Wall S: Can a sustainable community intervention reduce the health gap? 10-year evaluation of a Swedish community intervention programme for prevention of cardiovascular disease. Scand J Public Health 2001;56:59-68. 